\title{
Chemical Engineers: Untold Contribution to Humanity
}

\author{
Tony Green* \\ Department Chemical Engineering, University of Delaware, USA
}

Submission: January 25, 2018; Published: August 22, 2018

"Corresponding author: Tony Green, Department Chemical Engineering, University of Delaware, USA; Email: tonygreen@mytonygreen.com

Keywords: Chemical Engineers; Contribution; Humanity; Speaker; Politics; Industry; Business, Government; Technical; Attitude; Transform; Crude oil; Gasoline

\section{The Dilemma}

My introduction to this topic came from a presentation I attended. The speaker mentioned engineers are not involved in politics. The assertion seemed harsh at first, until I did the research and found that the speaker was correct. The fact is, most American engineers choose to focus on careers in Industry and business, notgovernment or policy. In contrast, their counterparts around the globe are more likely to indulge in politics.Only two U.S. presidents, Herbert Hoover and Jimmy Carter, have been engineers. In China, engineersare acknowledged as key players in the country's rapid economic rise. They're overrepresented in theChinese Politburo and among government ministers. These engineer-trained politician's role on thepolitical stage is a reason for the country's success.

\section{Experience}

My experience had led me to realize that the typical engineering attitude to a public policy issue is: "Oh, that's not a technical problem, so I have nothing to contribute." Sound familiar?

\section{The Chemical Engineering Profession}

Chemical engineering is the branch of engineering that processes raw material into different products by physical, chemical or biological means. Today, chemical engineers work in a range of industries designing, building and operating processes that transform crude oil into gasoline and plastics produce a range of specialty products like raw milk, and capture carbon from the smoke stacks of coal fired power stations.

\section{Principles of Chemical Engineers}

Chemical engineers need to understand the principles of a range of topics including biological processes,control of processes, fluid flow, heat transfer, mass transfer, material balances, momentum transport,process dynamics, process equipment design, reaction processes, safety, separation processes, solidhandling, sustainability and thermodynamics. In addition to possessing technical knowledge and skills,engineers are problem solvers able to break complex problems into more manageable tasks. GoodChemical engineers must be effective communicators, be able to work in teams, and possess a sound. Understanding of management practices and process economics.

\section{The Chemical Engineering Contribution}

The contributions of chemical engineers to society cannot be disputed. Some examples include Fritz Fisher and Carl Bosch, who worked out how to capture nitrogen from the air and convert it to ammonia, thus creating the world famous process that feeds the world. The Haber process is still important today because it produces ammonia, which is needed for fertilizer and many other purposes.Other instances include Jasper Kane and John McKeen of Pfizer, who took penicillin from AlexanderFleming's Petri dish and figured out how to grow it at scale, giving Allied soldiers a key advantage duringa critical stage ofWorld War II. The introduction of penicillin in the 1940's, which began the era ofantibiotics, has been recognized as one of the greatest advances in therapeutic medicine.Of course, we cannot forget Andrew Grove, who was the rags to riches pioneer who helped usher in the computer age at Intel. The realm of integrated chips is typically assumed to be within the realm of electrical engineering and computer science; however, these are produced by chemical processes.

\section{The Impact on Humanity and the Need for Policies}

The contributions I touched on were very technically oriented, but the more important contributions we as chemical engineers can make, given our training, relates to the non technical aspect of implementing our technology and creations.In the past, engineers were most concerned with how to effectively and profitably turn materials intousable products. Now, we might also consider how to build solutions that more efficiently use gas 
andother energy resources. Additionally, we need to consider whether any chemicals used are harmful tothe environment. Moving forward, non-technical contributions may be required. Technical leaders need to take a central role in trying to explain technology in ways that non-technicalpeople can understand. As I have learned during past presentations, people tend to resist ideas they donot understand. Furthermore, many of our politicians need to have a basic understanding of the idea ofthe policies they vote for.In countries like Iran, engineers are known for being politically active. The reason is that they can seethings from angles other people cannot, in democracies, lawyers shape the policy making procedures. This is not surprising. The law deals with the same sort of questions as politics: what makes a just society, the balance between liberty and security, and so on Lawyerly skills marshalling evidence, appealing to juries, and command of procedure transfer well to the political stage.

\section{Policy}

Policy is usually based on what politicians perceive as vote winners, or in lines their personal interests, rather than on evidence or data. Which begs the question: could an engineer trained politician or aide help this process? Many public policy issues are based on science and technology content. Engineers working with policy is the key to economic growth and ensuring the inventions created by engineers have the most impact on humanity.

\section{Politics is our problem}

In summary, politics is your problem and my problem, and if these problems are not solved they will become humanity's problem.

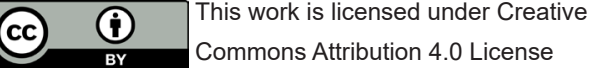

